\title{
High Conservation of Hepatitis B Virus Surface Genes during Maternal Vertical Transmission despite Active and Passive Vaccination
}

\author{
Hai-Xia Su $^{\text {a }}$ Yu-Hai Zhang ${ }^{b}$ Zhi-Guo Zhang ${ }^{a}$ Duan Lia Jing-Xia Zhang ${ }^{a}$ \\ Ke Men ${ }^{a}$ Lei Zhang ${ }^{a}$ Yong Long ${ }^{a}$ De-Zhong $\mathrm{Xu}^{\mathrm{a}}$ Yong-Ping Yan ${ }^{\mathrm{a}}$ \\ Departments of ${ }^{\mathrm{a}}$ Epidemiology and ${ }^{\mathrm{b}}$ Health Statistics, Faculty of Preventive Medicine, Fourth Military Medical \\ University, Xi'an, China
}

\section{Key Words}

Hepatitis B virus • Vertical transmission · Heterogeneity •

Mutation

\begin{abstract}
Objective: Our purpose was to explore the relationship between hepatitis B virus (HBV) gene heterogeneity and maternal vertical transmission. Methods: HBsAg-positive mothers and their neonates were selected and classified into a vertical infection neonate group (group $\mathrm{N}$ ), a vertical infection mother group (group $M$ ) and a control group (group C). Serum $\mathrm{HBsAg}$ and $\mathrm{HBeAg}$ were examined. HBV gene fragments, including the pre-S1, and pre-S2 and S coding regions, were amplified and sequenced, and the genotype and serotype of the sequences were identified. Mutation sites and frequency of mutations were then compared between group N and group C. Results: A total of $104 \mathrm{HBV}$ clone sequences were obtained. All obtained sequences belonged to genotype $C$ and serotype adr. Upon comparing sequences between group $\mathrm{N}$ and group $\mathrm{C}, 4$ nonsynonymous mutations were found with significant difference in mutation frequency $(p<0.05)$. When the mothers were both $\mathrm{HBsAg}$ and HBeAg positive, 10 nonsynonymous mutations were found. The frequencies of these mutations were significantly lower in group $N$ than in group $C(p<0.05)$. Conclusion: The $10 \mathrm{HBV}$ mutations were negatively associated
\end{abstract}

with vertical transmission when maternal HBeAg was positive. Furthermore, the species that were vertically transmitted to the fetus were mainly wild-type.

Copyright $\odot 2010$ S. Karger AG, Basel

\section{Introduction}

Although newborns with HBsAg-positive mothers are immunized with the hepatitis $B(\mathrm{HB})$ vaccine and hepatitis B immunoglobulin (HBIG) after birth, vertical transmission of HBV could not be completely prevented by this method. After infection either before or at birth, approximately $80-90 \%$ of the neonates become chronic asymptomatic carriers and some develop hepatitis $[1,2]$. In China, vertical transmission is one of most common transmission routes for hepatitis B virus (HBV) [2]. Thus, preventing vertical transmission has become a key measure to control the spread of hepatitis B in China [1]. However, the mechanism of vertical infection is unclear. Multiple factors may be involved in infection, such as the maternal serological status, molecular biological characteristics of the virus and susceptibility of the fetus.

\section{H.-X.S. and Y.-H.Z. contributed equally to this paper.}

\section{KARGER}

Fax +41613061234 E-Mail karger@karger.ch www.karger.com
(C) 2010 S. Karger AG, Basel

0300-5526/11/0543-0122\$38.00/0

Accessible online at:

www.karger.com/int
Yong-Ping Yan and De-Zhong $\mathrm{Xu}$

Department of Epidemiology, Fourth Military Medical University

No. 17, Changle West Road, Xi'an 710033 (China)

E-Mail yanyping@fmmu.edu.cn,xudezh@fmmu.edu.cn 
If the mother is positive for both $\mathrm{HBsAg}$ and $\mathrm{HBeAg}$ and her baby does not receive immunoprophylaxis, the risk of the baby developing an HBV infection by the age of 6 months is $70-90 \%$, and about $90 \%$ of them remain chronically infected $[3,4]$. If the mother is HBeAg negative, the risk of perinatal infection among infants is 10 $40 \%$, and $40-70 \%$ of these infants remain chronically infected [3-5]. The majority of these infected infants are asymptomatic carriers and mainly become infected from vertical transmission. Even with immunoprophylaxis, perinatal transmission may occur. Boot et al. [6] evaluated HBV infections in babies in the Netherlands who were born to HBsAg-positive women and received passive immunization with $\mathrm{HB}$ vaccinations. They found that 12 of 1,743 babies $(0.7 \%)$ were HBV infected. In Korea, despite administration of the HBIG and HB vaccine to infants with HBsAg-positive mothers, the failure rate of HBV immunoprophylaxis was $4.2 \%$ in 2008 [7]. In an Australian study, Wiseman et al. [8] reported that the rate of perinatal HBV transmission from HBV DNA-positive mothers was 4/138 (3\%), while the rate was 4/61 (7\%) from HBeAg-positive mothers and $4 / 47$ (9\%) from mothers with very high HBV DNA levels. In China, combining HB vaccine with HBIG resulted in a protection rate of $95-97 \%$ in the neonates born to HBsAg-positive mothers, and inoculation with the $\mathrm{HB}$ vaccine alone led to a protection rate of $87.8 \%$ of the newborn infants [1]. Xu et al. [9] found that 3.7\% of the infants born to HBsAg-positive mothers were HBsAg positive within $24 \mathrm{~h}$ of birth. In the women who were $\mathrm{HBeAg}$ positive, the intrauterine infection rate was $9.8 \%$.

The failure of HBV immunoprophylaxis may be attributed to many causes, such as vertical transmission, viral mutation, maternal blood infectivity, low response to the vaccine and inadequate immunization. Escape mutations of HBsAg have occasionally been found in infants with failed immunoprophylaxis. For example, the prevalence of 'a' determinant mutants (amino acids 121-149 of HBsAg) in vaccinated Taiwanese carrier children was $7.8-25 \%$ from 1984 to 2004 [10, 11]. Ni and Chen [11] thought that mutations in the 'a' determinant play some roles in infecting immunized children. In most cases, 'a' determinant vaccine escape mutants were not found in infected babies despite immunoprophylaxis [12, 13], suggesting that vaccine escape variants are not an important cause of failure to prevent $\mathrm{HBV}$ vertical transmission.

In a previous study, we found that the main risk factors for transplacental transmission of HBV were maternal serum $\mathrm{HBeAg}$ positivity, history of threatened preterm labor and virus existing in the villous capillary endothelial cells of the placenta [9]. The majority of HBsAg-positive pregnant women are asymptomatic chronic carriers, with a pool of quasi-species of HBV in their sera. The characteristics of the viral genome from all pregnant women were not fully consistent, which may be related to the outcome of vertical transmission. We analyzed the relationship between HBV gene heterogeneity and intrauterine infection in previous studies, and we found that the fetuses from mothers in whose sera HBV strains had certain mutations were not easily infected $[14,15]$. However, there was possible confounding bias from the maternal serum HBeAg status because it was an important risk factor. In this study, we added some subjects, compared the HBV sequences from the vertical infection group and control group after stratification by maternal HBeAg status and analyzed the characteristics of the viral genome. The aim of this study was to identify significant virology factors to elucidate the mechanism of vertical infection.

\section{Materials and Methods}

Subjects and Specimen Collection

The subjects included HBsAg-positive mothers and their neonates. Full-term mothers were admitted for delivery to the Maternal and Child Health Hospital of Shaanxi Province, Xi'an, China, between August 1997 and 2002. HBsAg-positive mothers did not receive $\mathrm{HB}$ vaccine and $\mathrm{HBIG}$ before or during pregnancy and did not receive antiviral treatment during pregnancy. Signs of premature delivery and abortion were not found in any of the pregnancies. All subjects signed an informed consent form and were assured that personal information would be confidential.

Venous blood specimens from the pregnant women and femoral vein blood specimens from neonates were obtained within $24 \mathrm{~h}$ after birth and before immunoprophylaxis. Sera were separated and stored at $-20^{\circ}$ for testing of HBV markers. Neonates were immunized with high-titer HBIG and $\mathrm{HB}$ vaccine within $24 \mathrm{~h}$ after birth. Vaccination followed the 0-, 1- and 6-month schedule.

\section{Criteria for HBV Vertical Transmission}

Occurrence of $\mathrm{HBV}$ vertical transmission was defined as when neonate venous blood specimens were positive for both HBsAg and HBV DNA within $24 \mathrm{~h}$ after birth and before immunoprophylaxis, blood specimens were still positive in the first or seventh month, and the mother was an HBsAg carrier.

Six neonates who met these criteria were classified as the vertical infection neonate group (group N), and their HBsAg-positive mothers were classified as the vertical infection mother group (group M). Thirteen HBsAg-positive mothers whose neonates were negative for both HBsAg and HBV DNA at birth from the same study population were selected and classified as the control group (group C).

All mothers from groups $\mathrm{M}$ and $\mathrm{C}$ were positive for both HBsAg and HBV DNA but negative for antibodies against hepatitis $\mathrm{A}, \mathrm{C}, \mathrm{D}$ and $\mathrm{E}$. The fathers of the neonates in group $\mathrm{N}$ were not infected by HBV. 


\section{HBV Serological Marker Assay}

Serum HBsAg and HBeAg were examined by enzyme-linked immunosorbent assay (ELISA), using a commercial kit (Kehua, Shanghai, China). The results were evaluated by a Multiskan MK3 ELISA detector. Positive/negative $\geq 2.1$ were considered positive.

\section{HBV PCR Amplification and Sequencing}

PCR of a 1.2-kb fragment of the HBV genome including the pre-S1, pre-S2 and $S$ coding regions was performed on serum samples as follows. HBV DNA was extracted using a commercially available kit (QIAmp DNA blood mini-kit, Qiagen Inc., USA) and then amplified with the high-fidelity PCR System (Roche Corporation) according to the manufacturers' specifications using the following primer pairs: 5'-CGGGATCCCATATTCTTGGGAACAAG-3' (nt2826-2844) and 5'-CACTGCAGGGTTTAAATGTATACCCA-3' (nt839-821) [14]. The PCR conditions were as follows: $5 \mathrm{~min}$ at $94^{\circ}$ followed by 35 amplification cycles of $45 \mathrm{~s}$ at $94^{\circ}, 1 \mathrm{~min}$ at $60^{\circ}$ and $2 \mathrm{~min}$ at $72^{\circ}$. Optimal positive and negative controls were included in each extraction and amplification process.

PCR-amplified viral DNA was separated by gel electrophoresis, recovered and digested by restriction enzymes PstI and BamHI. HBV DNA fragments were ligated to the pUC19 plasmid vector and transformed into competent Escherichia coli DH5a cells. Clones from each of the subjects were then obtained. Plasmid DNA from a single transformant colony was extracted and verified with restriction enzyme digests and sequencing. Automatic sequencing was carried out using an ABI 3100 DNA automatic sequencer (Applied Biosystems Inc., USA) by Beijing AuGCT Biotechnology Co.

\section{Genotype and Sequence Analysis}

Genotypes were identified based on 96\% homology with S genes of different genotypes. Serotypes were determined based on HBsAg amino acids 122, 127, 160 and 159 [16]. To define the $\mathrm{HBV}$ genotype, sequences of isolates were compared with a set of GenBank reference sequences with known HBV A-H genotypes. The accession numbers of the 8 reference sequences were as follows: X02763 [17], D00329 [18], M12906 [19], X02496 [20], X75664, X75663 [16], AF160501 [21] and AY090454 [22]. The HBV genotype was confirmed by constructing phylogenetic trees with the Kimura 2-parameter model and calculating the similarity rate with references sequences. The statistical robustness within each phylogenetic tree was confirmed with a bootstrap analysis using 1,000 replicates. Phylogenetic analysis was performed with Clustal 1.8 and MEGA 4.1. Sequence similarity and mutation positions of nucleotide and amino acid sequences were analyzed by the DNASTAR software package (DNASTAR Inc., Madison, Wisc., USA). Multiple comparisons of all clone sequences with each reference sequence (genotypes $\mathrm{A}-\mathrm{H}$ ) were carried out by the ClustalW program integrated in MegAlign software, and the similarity rates of each genotype were obtained and presented as means \pm standard deviation.

\section{Statistical Analysis}

Mutation Analysis

A nucleotide substitution in an isolated sequence compared with the HBV reference sequence of Chinese with $C$ genotype (Chinese HBV-C) $[23,24]$ was considered a point mutation. Point mutations that were found in only 1 sequence or from 1 subject were not calculated and analyzed. The frequency of subjects with specific point mutations and frequency of clones with specific point mutations were calculated. The difference in frequencies between 2 groups was assessed by Fisher's exact test and corrected for multiple testing with the Benjamini-Hochberg method at a false discovery rate of 0.05 .

\section{Mutation Covariation}

The covariation among specific point mutations was investigated by calculating the binomial correlation coefficient $(\phi)$ for the simultaneous presence of mutations at 2 positions in the same isolate. Statistically significant pairs of mutations were assessed by Fisher's exact test and corrected for multiple testing with the Benjamini-Hochberg method (false discovery rate $=0.05$ ).

\section{Cluster Analysis}

Mutational clusters [25] were defined as clusters of $\geq 3 \mathrm{mu}$ tated positions which were significantly correlated with each other and were identified using an average linkage hierarchical agglomerative clustering. The details of this data analysis procedure have been described elsewhere [26, 27].

Briefly, the $\phi$ coefficients were transformed to dissimilarity values by mapping $\phi=1$ (maximal positive association) to dissimilarity 0 and $\phi=-1$ (maximal negative association) to dissimilarity 1 , with linear interpolation in between. The resulting partial dissimilarity matrix was then used as the input for average linkage hierarchical agglomerative clustering, and undefined dissimilarity values were ignored in computing average dissimilarities between clusters. In order to assess the stability of the resulting dendrogram, confidence values for all subtrees in the dendrogram were computed by 100 replicates of the clustering procedure on sequence sets bootstrapped from the original 47 clone sequences $[28,29]$. Higher bootstrap values indicate that the association of mutations into a group is not due to sampling bias.

Statistical analysis was performed by software SPSS version 16 (SPSS Inc., Chicago, Ill., USA) on a computer. The difference in mean age and gender was analyzed by Student's t test and Fisher's exact test. Similarities of all clones isolated with each of the 8 genotypes of reference strains were analyzed by ANOVA test, and the difference in similarities between 2 genotypes was analyzed by Dunnett's t test. $\mathrm{p}<0.05$ was considered statistically significant.

\section{Results}

\section{Subject Characteristics}

A total of $457 \mathrm{HBsAg}$-positive mothers and their 461 neonates (including 4 sets of twins) joined this study and completed the survey and test for HBV markers. Among the subjects, 79 mothers were $\mathrm{HBeAg}$ positive and $7 \mathrm{ba}-$ bies were persistently positive for HBsAg. Twenty-six of 33 neonates who tested positive for HBsAg within $24 \mathrm{~h}$ of birth became negative after immunization. Six of 7 babies infected by HBV were entered into group $\mathrm{N}$; the other baby was excluded because of failure to amplify the $1.2-\mathrm{kb}$ fragment of the HBV genome. 
Table 1. Main characteristics and HBV serological status of subjects

\begin{tabular}{|c|c|c|c|c|c|c|c|c|}
\hline \multirow[t]{2}{*}{ Groups } & \multirow[t]{2}{*}{ Subjects } & \multicolumn{4}{|l|}{ Mothers } & \multicolumn{3}{|c|}{ Newborns } \\
\hline & & HBsAg & HBeAg & age, years & clones & HBsAg & gender & clones \\
\hline \multirow{6}{*}{$\begin{array}{l}\text { Vertical in- } \\
\text { fection group }\end{array}$} & M1 & + & + & 24 & 6 & + & male & 5 \\
\hline & M2 & + & + & 26 & 5 & + & male & 6 \\
\hline & M3 & + & - & 25 & 5 & + & female & 6 \\
\hline & M4 & + & + & 24 & 5 & + & female & 5 \\
\hline & M5 & + & + & 28 & 5 & + & male & 6 \\
\hline & M6 & + & + & 24 & 5 & + & female & 4 \\
\hline \multirow[t]{13}{*}{ Control group } & $\mathrm{C} 1$ & + & + & 23 & 3 & - & female & ND \\
\hline & $\mathrm{C} 2$ & + & + & 25 & 3 & - & male & ND \\
\hline & C3 & + & + & 24 & 3 & - & female & ND \\
\hline & $\mathrm{C} 4$ & + & + & 26 & 2 & - & male & ND \\
\hline & $\mathrm{C} 5$ & + & + & 28 & 2 & - & male & ND \\
\hline & C6 & + & + & 26 & 2 & - & male & ND \\
\hline & C7 & + & + & 24 & 3 & - & female & ND \\
\hline & $\mathrm{C} 8$ & + & + & 23 & 3 & - & female & ND \\
\hline & $\mathrm{C} 9$ & + & - & 25 & 4 & - & male & ND \\
\hline & $\mathrm{C} 10$ & + & - & 25 & 4 & - & female & ND \\
\hline & C11 & + & - & 24 & 4 & - & male & ND \\
\hline & $\mathrm{C} 12$ & + & - & 27 & 4 & - & male & ND \\
\hline & $\mathrm{C} 13$ & + & - & 24 & 4 & - & female & ND \\
\hline
\end{tabular}

$+=$ Positive for HBV marker; - = negative for HBV marker; ND = not done

The mothers from group $\mathrm{M}$ and group $\mathrm{C}$ were ethnic Han women with mean ages of $25.17 \pm 1.6$ and 24.54 \pm 1.26 , respectively ( $t=0.927, \mathrm{p}=0.367$, Student's $\mathrm{t}$ test). There was no difference in gender distribution between group $\mathrm{N}$ ( 3 male: 3 female) and neonates of group $\mathrm{C}(8$ male: 5 female) (Fisher's exact test, $\mathrm{p}=1.000$ ). There were $5 \mathrm{HBeAg}$-positive mothers in group $\mathrm{M}$ and 8 in group $\mathrm{C}$. The main characteristics and the HBV serological status of the different groups are listed in table 1.

\section{Genotype and Serotype}

After cloning and sequencing, $104 \mathrm{HBV}$ clones, including 31 clones from group $\mathrm{M}, 32$ clones from group $\mathrm{N}$ and 41 clones from group $\mathrm{C}$, were obtained in total. These clones included 1.2-kb fragments of the HBV genome from the pre-S1 region to the $S$ region.

The neighbor-joining phylogenetic tree with 1,000 bootstrap replications was constructed on $1.2-\mathrm{kb}$ gene fragments of genotype A-H reference sequences, Chinese HBV-C $[23,24]$ and 104 clone sequences (fig. 1). In this neighbor-joining tree, all obtained sequences were clearly clustered into genotype C (M12906). Compared with the $\mathrm{A}-\mathrm{H}$ genotypes reference sequences, all clone sequences were most similar to the reference sequence of genotype $\mathrm{C}$ among the 8 genotypes. The mean similarity rate of the $C$ genotype was $97.42 \pm 0.57 \%$, which was significantly higher than that of the other genotypes, ranging from $85.00 \pm 0.17$ to $92.23 \pm 0.20 \%$ (1-way ANOVA, $F=11,749.36, \mathrm{p}<0.001 ;$ Dunnett's $\mathrm{t}$ test, $\mathrm{p}<0.001)$. Then all clone sequences compared with the Chinese HBV-C sequence, the mean similarity rate was $98.17 \pm 0.60 \%$, indicating that the $104 \mathrm{HBV}$ clones belonged to genotype $\mathrm{C}$, and their serotypes were adr based on HBsAg amino acids 122, 127, 160 and 159 [16, 30]. These HBV sequences isolated from subjects were consistent with the genotype and serotype distributions of HBV in China [23, 28, 31].

The mean similarity rates of nucleotide sequences in each pair of mother and neonate in the vertical infection group were 99.55, 99.33, 99.44, 99.36, 99.55 and 98.96\%. The high similarity rates indicated a remarkable consistency and homology from mother to neonate.

\section{Mutation Sites of Nucleotide and Amino Acid \\ Sequences}

The majority of the nucleotide sequence mutations were substitutions; few insertions or deletions of single nucleotides were observed in several sequences. To ex- 
Table 2. Significant HBV point mutations between 2 groups

\begin{tabular}{|c|c|c|c|c|c|c|}
\hline \multirow[t]{2}{*}{ Group } & \multirow[t]{2}{*}{ Patients } & \multicolumn{5}{|c|}{ Frequency of point mutation } \\
\hline & & $\mathrm{C} 2875 \mathrm{~A}$ & G3212A & $\mathrm{T} 434 \mathrm{C}$ & $\mathrm{T} 462 \mathrm{C}$ & A802G \\
\hline Group N & 6 & $0(0)$ & $0(0)$ & $0(0)$ & $0(0)$ & $0(0)$ \\
\hline Group C & 13 & $7(53.8)$ & $7(53.8)$ & $7(53.8)$ & $7(53.8)$ & $8(61.5)$ \\
\hline $\mathrm{p}$ value & & 0.044 & 0.044 & 0.044 & 0.044 & 0.044 \\
\hline Amino acid & & Q10K & W3Stop & L448P & M103T & T571A \\
\hline substitution & & (pre-S1) & (pre-S2) & $(\mathrm{P})$ & $(\mathrm{S})$ & $(\mathrm{P})$ \\
\hline
\end{tabular}

Frequency of point mutation: the frequency of patients with a specific mutation divided by the total number of patients from 1 group (numbers of cases with percentages in parentheses). p values were assessed by Fisher's exact test and corrected with the Benjamini-Hochberg method. The amino acid site was counted from the methionine of the pre-S1, pre-S2 and S region, respectively.

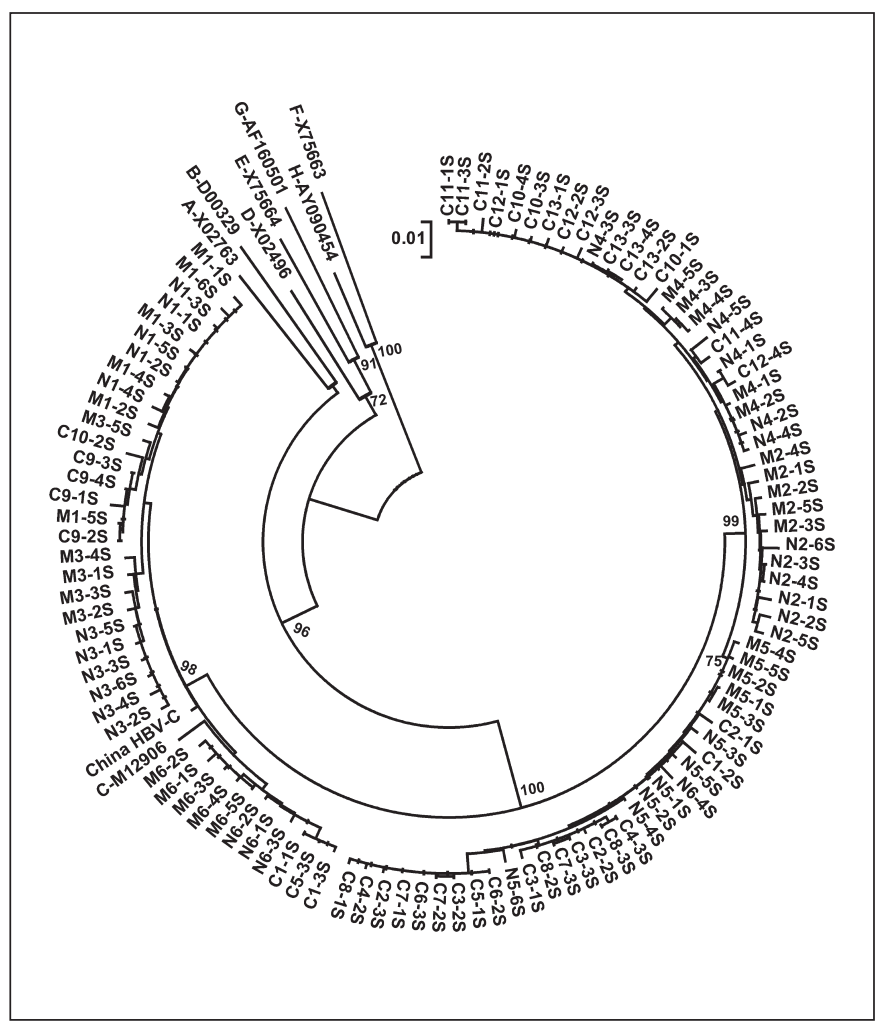

Fig. 1. The neighbor-joining phylogenetic tree constructed on the pre-S1, and pre-S2 and S gene of 9 reference nucleotide sequences and 104 cloned nucleotide sequences isolated from 6 pairs of mothers and neonates in the vertical infection group (group $M$ and group $\mathrm{N}$ ) and $13 \mathrm{HBsAg}$-positive mothers of the control group (group C). Reference sequences of HBV genotypes are denoted according their GenBank accession number. $\mathrm{N}=$ Neonates of group $\mathrm{N} ; \mathrm{M}=$ mothers of group $\mathrm{M} ; \mathrm{C}=$ mothers of group $\mathrm{C}$; Chinese HBV-C = HBV reference sequence of Chinese with $\mathrm{C}$ genotype. Bootstrap values (percentages, 1,000 replications) $>70$ are denoted in major branches. plore the relationship between HBV vertical infection and viral gene heterogeneity, we analyzed and compared virus sequences between group $\mathrm{N}$ and group $\mathrm{C}$. Five point mutations (C2875A, G3212A, T434C, T462C and A802G) were associated with vertical infection. The frequencies of mutations were significantly different between group $\mathrm{N}$ and group $\mathrm{C}(\mathrm{p}<0.05$; table 2$)$. The five nonsynonymous substitutions were located in the pre-S1, pre-S2, $\mathrm{S}$ and P regions. Particularly, G3212A was a nonsense mutation that resulted in a stop codon in the pre-S2 region and incomplete expression of large and middle HBsAg protein. This substitution was observed in 7 of 13 mothers from group $\mathrm{C}$ and was absent from group $\mathrm{N}$.

\section{Stratification Analysis by Maternal HBeAg Status}

$\mathrm{HBeAg}$ positivity is an important risk factor for $\mathrm{HBV}$ vertical infection and perinatal transmission $[9,29]$. A fetus whose mother is positive for both HBsAg and HBeAg is easily infected by HBV $[9,29,32]$. Therefore, the subjects in the 2 groups were stratified by maternal $\mathrm{HBeAg}$ status to exclude possible confounding bias. Because there was only 1 neonate of group $\mathrm{N}$ whose mother was negative for $\mathrm{HBeAg}$, we did not compare his sequences with that of the HBeAg-negative mothers from group C. We obtained $26 \mathrm{HBV}$ sequences from 5 neonates with HBeAg-positive mothers of group $\mathrm{N}$ and $21 \mathrm{HBV}$ sequences from $8 \mathrm{HBeAg}$-positive mothers of group C (table 1). The mothers' ages and the neonates' genders were balanced between group $\mathrm{N}$ and group $\mathrm{C}$. The mean divergences of nucleotide sequences and amino acid sequences were $1.87 \pm 0.76$ and $1.68 \pm 0.60 \%$ in group $\mathrm{N}$ and 2.88 \pm 0.67 and $2.24 \pm 0.51 \%$ in group $C$, which were not significantly different between the two groups $(t=3.362$, 
Table 3. Significant HBV point mutations between 2 groups after stratification by maternal HBeAg positivity

\begin{tabular}{|c|c|c|c|c|c|c|c|c|c|c|c|}
\hline \multirow[t]{2}{*}{ Group } & \multirow[t]{2}{*}{ Patients } & \multicolumn{10}{|c|}{ Frequency of point mutation } \\
\hline & & $\mathrm{C} 2875 \mathrm{~A}$ & $\mathrm{C} 3000 \mathrm{~A}$ & G3212A & A162G & C339T & $\mathrm{T} 434 \mathrm{C}$ & $\mathrm{T} 462 \mathrm{C}$ & T531G & A802G & $\mathrm{T} 810 \mathrm{C}$ \\
\hline Group N & 5 & $0(0)$ & $2(40.0)$ & $0(0)$ & $2(40.0)$ & $2(40.0)$ & $0(0)$ & $0(0)$ & $0(0)$ & $0(0)$ & $0(0)$ \\
\hline Group C & 8 & $7(87.5)$ & $8(100.0)$ & $7(87.5)$ & $8(100.0)$ & $8(100.0)$ & $7(87.5)$ & $7(87.5)$ & $7(87.5)$ & $7(87.5)$ & $7(87.5)$ \\
\hline $\mathrm{p}$ value & & 0.007 & 0.035 & 0.007 & 0.007 & 0.035 & 0.007 & 0.007 & 0.007 & 0.007 & 0.007 \\
\hline Amino acid & & Q10K & H51Q & W3Stop & N3S & P62L & L448P & M103T & $\mathrm{I} 126 \mathrm{~S}$ & T571A & $\mathrm{F} 219 \mathrm{~S}$ \\
\hline substitution & & (pre-S1) & (pre-S1) & (pre-S2) & $(\mathrm{S})$ & $(\mathrm{S})$ & $(\mathrm{P})$ & $(\mathrm{S})$ & $(\mathrm{S})$ & $(\mathrm{P})$ & (S) \\
\hline
\end{tabular}

Frequency of point mutation: the frequency of patients with a specific mutation divided by the total number of patients from 1 group (numbers of cases with percentages in parentheses). $\mathrm{p}$ values were assessed by Fisher's exact test and corrected with the Benjamini-Hochberg method. The amino acid site was counted from the methionine of the pre-S1, pre-S2 and S region, respectively.

$\mathrm{p}=0.069 ; t=4.787, \mathrm{p}=0.648$, respectively). Ten mutations (C2875A, C3000A, G3212A, A162G, C339T, T434C, T462C, T531G, A802G and T810C) were associated with vertical infection, all of which had significant differences in frequency of occurrence between group $\mathrm{N}$ and group $\mathrm{C}$ ( $\mathrm{p}$ values from 0.007 to 0.035 ) (table 3 ). Five mutations (C2875A, G3212A, T434C, T462C and A802G) were also found with significant difference in unstratified results (table 2).

The positions of 10 nonsynonymous substitutions in the HBV genome are shown in table 3. Q10K and H51Q were located in the pre-S1 region, W3Stop in the pre-S2 region, NS3, P62L, M103T, I126S and F219S were in the S region, and $\mathrm{L} 448 \mathrm{P}$ and T571A in the P region. These substitutions were mainly found in group $\mathrm{C}$ and occurred at lower frequencies or were absent from sequences of group N. The mutations Q10K, W3Stop, L448P, M103T, I126S, T571A and F219S were completely absent from group N and occurred with a frequency of $87.5 \%$ in group C. These 7 mutations were not found in the mothers of group $M$ either. Mutations H51Q, N3S and P62L occurred with a lower frequency $(40.0 \%)$ in group $\mathrm{N}$ and at a higher frequency $(100 \%)$ in group C. The 3 mutations were also found in one of the mothers of group $\mathrm{M}$. None of the 10 mutations were found in the $5 \mathrm{HBeAg}$-negative control mothers, with the exception of A802G, which was observed in 1 mother.

Interestingly, these mutations seemed to be divided into 2 clusters and show covariation. To identify significant covariation patterns of pairwise correlations of the 10 mutations in 47 clone sequences of group $\mathrm{N}$ and group C, we calculated the binomial correlation coefficient $(\phi)$ and its statistical significance for major mutation pairs (table 4). The Q10K mutation, along with 6 other muta- tions (W3Stop, L448P, M103T, I126S, T571A and F219S), were positively correlated $(\phi=0.936)$. Mutations H51Q, N3S and P62L were also positively correlated ( $\phi$ from 0.918 to 0.958 ). To confirm the 2 covariation clusters, we performed an average linkage hierarchical agglomerative cluster analysis. The topology of the dendrogram (fig. 2) suggested that the 10 mutations were divided into 2 clusters. Cluster I comprised Q10K, W3Stop, L448P, M103T, I126S, T571A and F219S, and cluster II comprised H51Q, N3S and P62L. All mutations of each covariation cluster were simultaneously present or absent from the same clone sequence. It may be associated with the phylogenetic relationship of sequences. The 9 clone sequences from group C (including C6-2, C5-1, C3-2, C7-2, C6-3, C7-1, C2-3, C4-2 and C8-1) with cluster I and II mutations belonged to a close phylogenetic group (fig. 1). Another 7 clone sequences from group C (including C4-3, C8-3, C22, C3-3, C7-3, C8-2 and C3-1) with cluster II mutations also belonged to another close phylogenetic group (fig. 1).

\section{Discussion}

In this study, when mothers were positive for $\mathrm{HBsAg}$ and $\mathrm{HBeAg}$, the frequencies of 10 point mutations of $\mathrm{HBV}$ were significantly lower in neonates of the vertical infection group than in mothers of control group, and the species that vertically transmitted to fetus were predominantly wild-type. This finding suggests that the $10 \mathrm{HBV}$ mutations were negatively associated with vertical transmission when maternal $\mathrm{HBeAg}$ was positive.

In our previous studies $[14,15]$, we analyzed the relationship between intrauterine HBV infection and virus gene heterogeneity by comparing HBV sequences from 
Table 4. Significantly correlated pairs of mutations

\begin{tabular}{|c|c|c|c|c|c|c|}
\hline \multirow[t]{2}{*}{ Mutation A } & \multirow[t]{2}{*}{ Frequency } & \multicolumn{2}{|c|}{ Correlated mutation } & \multirow{2}{*}{$\begin{array}{l}\text { Covariation } \\
\text { frequency }^{\mathrm{b}}\end{array}$} & \multirow[t]{2}{*}{$\phi$} & \multirow[t]{2}{*}{$\mathrm{p}$ value } \\
\hline & & mutation B & frequency ${ }^{\mathrm{a}}$ & & & \\
\hline \multirow[t]{6}{*}{ Q10K } & \multirow{6}{*}{$10(21.3)$} & W3Stop & $9(19.1)$ & $9(90.0)$ & 0.936 & $1.38 \times 10^{-10}$ \\
\hline & & L448P & $9(19.1)$ & $9(90.0)$ & 0.936 & $1.38 \times 10^{-10}$ \\
\hline & & M103T & $9(19.1)$ & $9(90.0)$ & 0.936 & $1.38 \times 10^{-10}$ \\
\hline & & I126S & $9(19.1)$ & $9(90.0)$ & 0.936 & $1.38 \times 10^{-10}$ \\
\hline & & $\mathrm{T} 571 \mathrm{~A}$ & $9(19.1)$ & $9(90.0)$ & 0.936 & $1.38 \times 10^{-10}$ \\
\hline & & F219S & $9(19.1)$ & $9(90.0)$ & 0.936 & $1.38 \times 10^{-10}$ \\
\hline \multirow[t]{2}{*}{ N3S } & \multirow[t]{2}{*}{$26(55.3)$} & H51Q & $25(53.2)$ & $25(96.2)$ & 0.958 & $5.10 \times 10^{-11}$ \\
\hline & & P62L & $24(51.1)$ & $24(92.3)$ & 0.918 & $3.10 \times 10^{-10}$ \\
\hline
\end{tabular}

Figures are numbers of cases with percentages in parentheses.

${ }^{a}$ Frequencies of mutations in 47 cloned sequences of group $\mathrm{N}$ and group $\mathrm{C}$ were determined.

${ }^{b}$ Percentages were calculated for sequences containing each A mutation.

$\mathrm{p}$ values for covariation were significant at a false discovery rate of 0.05 following correction for multiple comparisons.

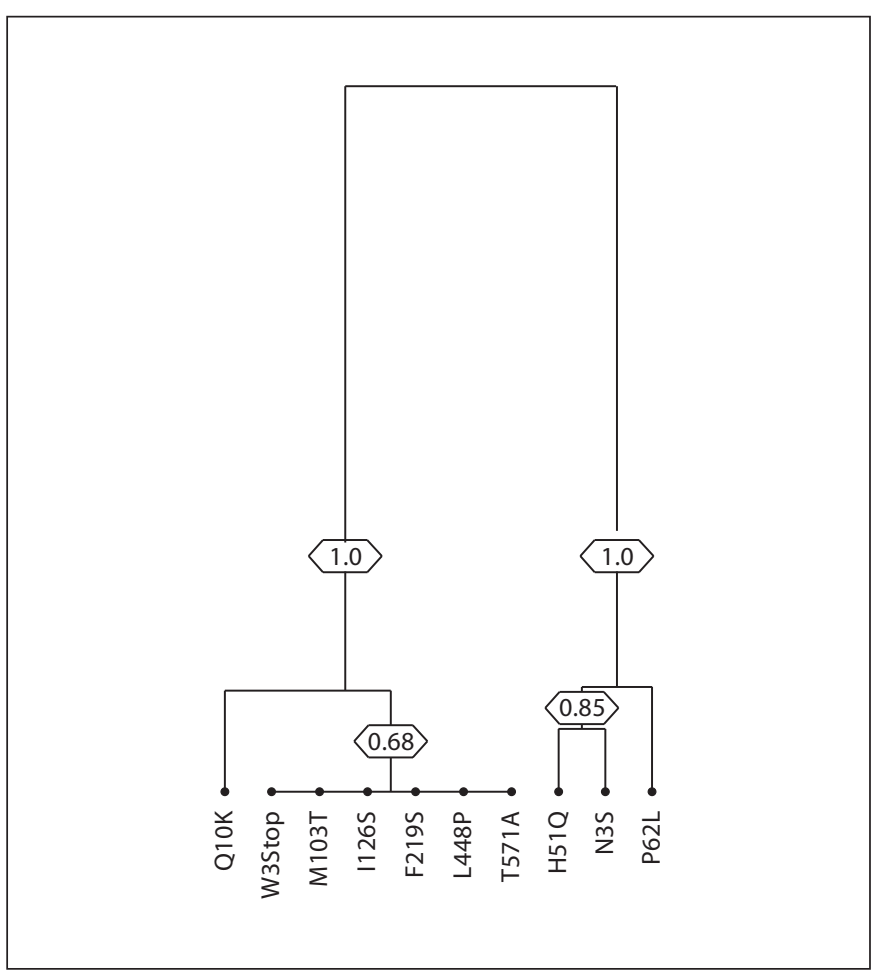

Fig. 2. Dendrogram obtained from average linkage hierarchical agglomerative clustering, showing 2 clusters of covariation from $47 \mathrm{HBV}$ nucleotide sequences of group $\mathrm{N}$ and group $\mathrm{C}$. The length of the branches reflects the distances between mutations in the original distance matrix. Bootstrap values, indicating the significance of clusters, are reported in the boxes. mothers (group $\mathrm{M}$ ) and neonates (group N) of the intrauterine $\mathrm{HBV}$ infection group and HBsAg-positive mothers from the noninfection group (group $\mathrm{C}$ ). We concluded that some specific HBV mutations were associated with intrauterine infection. In this study, we compared the HBV sequences between group $\mathrm{N}$ and group $\mathrm{C}$. The sequences from group $\mathrm{M}$ were not analyzed. It is difficult to clearly distinguish these species that were transmitted to the fetus from the mixed quasi-species pool of $\mathrm{HBV}$ in the mothers. In an HBsAg-positive mother, 1 species may have been transmitted to the fetus through the placenta, resulting in vertical infection, while other species may not have been transmitted in this way. The species obtained from group $\mathrm{N}$ were transmitted to the fetus by vertical transmission, while the species from group $\mathrm{C}$ were not transmitted due to the influence of virological character or maternal status. By comparing the nucleotide sequences between group $\mathrm{N}$ and group $\mathrm{C}, 5$ point mutations were found with significant differences in the frequency of mutations. These mutations were confirmed after stratification by maternal HBeAg-positivity.

Maternal HBeAg-positivity is an important risk factor in vertical transmission of $\mathrm{HBV}$, and it was correlated with the viral load. The viral load of HBeAg-positive carriers was often found to be higher than that of $\mathrm{HBeAg}$-negative carriers [29, 33, 34]. Furthermore, the HBV DNA levels in HBeAg-positive people were very high (approximately $10^{5}-10^{10}$ copies/ml in sera), whereas after HBeAg seroconversion, the levels may fall below $10^{4}$ copies $/ \mathrm{ml}$ [29]. The risk of perinatal infection is $5-20 \%$ in infants born to 
HBsAg-positive mothers and $70-90 \%$ in infants born to $\mathrm{HBeAg}$-positive mothers [32]. In this study, the $13 \mathrm{HBeAg}$ positive mothers from 2 groups did not display premature delivery and abortion during pregnancy. All neonates were immunized with HBIG and HB vaccine. Why were some neonates infected by vertical transmission and some not although their mothers were all positive for $\mathrm{HBeAg}$ ? The gene heterogeneity of the virus may contribute to vertical infection if the maternal factors were similar and the fetus was generally susceptible to HBV.

Escape mutations in the $\mathrm{S}$ gene encoding HBsAg are associated with passive or active immunization at a time point when the virus is already present in the host and possibly replicating, such as during failure of passive/active $\mathrm{HB}$ immunization in newborns of $\mathrm{HBV}$-infected mothers [35]. McMahon et al. [36] investigated breakthrough of HBV after successful active vaccination in a large study and found that escape mutants were rarely detected and accompanied by wild-type infection. The authors suggested that escape mutants seemed to play a minor role in breakthrough of $\mathrm{HBV}$ vaccination. Basuni et al. [12] screened vaccine escape mutations in infected children and their mothers in Pacific Island countries. Although the opportunity for the emergence of vaccine escape mutants in these populations was high, they found no 'a' determinant vaccine escape mutants. This finding suggests that vaccine escape variants are not an important cause of failure to prevent HBV transmission. Liu et al. [37] observed the influence of HBV gene heterogeneity on failure of $\mathrm{HBV}$ vaccination in eastern China, but they found no difference in the $S$ gene mutation rate or genotypes between the failure group and control group. However, high viral load is an important risk factor for failure of $\mathrm{HBV}$ vaccination.

In our study, we found 10 nonsynonymous mutations when comparing the HBV sequences of neonates from HBeAg-positive mothers of group $\mathrm{N}$ and $\mathrm{HBeAg}$-positive mothers of group $\mathrm{C}$. The frequencies of mutations in group $\mathrm{N}$ were significantly lower than that in group $\mathrm{C}$. The cluster I mutations, which included Q10K, W3Stop, L448P, M103T, I126S, T571A and F219S, were absent from group $\mathrm{N}$. The species transmitted to a fetus by vertical transmission was rarely mutated in the 10 amino acid positions, especially the 7 point mutations of cluster I. Although the results are preliminary, they may provide virologic and epidemiologic evidence for screening highrisk pregnant women for $\mathrm{HBV}$ vertical transmission and for developing more targeted interruption measures.

The 10 point mutations are potentially disadvantageous to the development of infection because they may influence entry and infectivity of virus. For example, the G3212A mutation was found to result in a stop codon at the third codon of the pre-S2 region, which terminated translation of L-HBsAg and M-HBsAg. Blanchet et al. [26] suggested that activity of the pre-S domain upon viral entry only depends on the integrity of the first $75 \mathrm{ami}$ no acids, while large deletions overlapping the pre-S2 domain were compatible with infectivity. In our study, the stop codon in the pre-S2 region resulted in deletion of approximately 180 amino acids of L-HBsAg and almost full deletion of M-HBsAg. Such a large deletion of envelope proteins probably affects viral attachment and entry into cells and is usually associated with a lower virus load. In this situation, passive or active vaccination could have a much better chance of preventing transmission. Now the related experiments on the infectivity of virus with the stop codon substitution are carried out in hepatocytes and trophoblastic cells.

The pre-S1 infectivity determinants were confined to the N-terminal 75 amino acid residues. In our study, the Q10K and H51Q substitutions in the pre-S1 region were prevalent in group $\mathrm{C}$, while few of these substitutions were observed in group $\mathrm{N}$. The 2 mutations were also found in HBeAg-negative asymptomatic carriers with low viral loads [34]. However, future experiments are required to determine if 1 or several nonsynonymous mutations in pre-S1 infectivity determinants influence infectivity of virus. The $126 \mathrm{~S}$ substitutions in the common 'a' determinant of the $S$ region was only observed in group C, so it may be associated with immunity escape $[7,38$, 39] and did not have the ability to reduce infectivity [27].

The other mutations in the $\mathrm{S}$ and $\mathrm{P}$ regions may have no obvious effect on immunoprophylaxis and infectivity. The functional significance of these mutants remains to be determined. The limitations in this study included a sample size that was small and the subject viral loads that were not measured. Now that we have begun a cohort study using HBsAg-positive pregnant women and their neonates, efforts will be made to enroll more subjects in this study, accurately detect correlative viral markers and pay greater attention to the effect of mutations on viral breakthrough after vaccination and viral infectivity to clarify the mechanism of HBV vertical infection.

\section{Acknowledgment}

This work was supported by the National Natural Science Foundation of China (No. 30230320) and partly by China Special Grant for the Prevention and Control of Infection Diseases (No. 2009ZX10002-027). 


\section{References}

$\checkmark 1$ Lu FM, Zhuang H: Management of hepatitis B in China. Chin Med J (Engl) 2009;122:3-4.

2 Zhou YH, Wu C, Zhang H: Vaccination against hepatitis $\mathrm{B}$ : the Chinese experience. Chin Med J 2008;121:98-102.

$\checkmark 3$ Stevens CE, Neurath RA, Beasley RP, Szmuness $\mathrm{W}$ : HBeAg and anti-HBe detection by radioimmunoassay: correlation with vertical transmission of hepatitis B virus in Taiwan. J Med Virol 1979;3:237-241.

-4 Tran TT: Management of hepatitis B in pregnancy: weighing the options. Cleve Clin J Med 2009;76(suppl 3):S25-S29.

5 Sinha S, Kumar M: Pregnancy and chronic hepatitis B virus infection. Hepatol Res 2010; 40:31-48.

6 Boot HJ, Hahne S, Cremer J, Wong A, Boland $G$, van Loon AM: Persistent and transient hepatitis B virus (HBV) infections in children born to HBV-infected mothers despite active and passive vaccination. J Viral Hepat 2009, Epub ahead of print

$\checkmark 7$ Park NH, Chung YH, Lee HS: Impacts of vaccination on hepatitis B viral infections in Korea over a 25-year period. Intervirology 2010;53:20-28.

$\checkmark 8$ Wiseman E, Fraser MA, Holden S, Glass A, Kidson BL, Heron LG, Maley MW, Ayres A, Locarnini SA, Levy MT: Perinatal transmission of hepatitis B virus: an Australian experience. Med J Aust 2009;190:489-492.

$\checkmark 9$ Xu DZ, Yan YP, Choi BC, Xu JQ, Men K, Zhang JX, Liu ZH, Wang FS: Risk factors and mechanism of transplacental transmission of hepatitis B virus: a case-control study. J Med Virol 2002;67:20-26.

-10 Huang ML, Liao WL, Ho MS: HBV serological markers of vaccinated children in remote areas of Taiwan: emphasis on factors contributing to vaccine failure. Vaccine 2007;25: 6326-6333.

11 Ni YH, Chen DS: Hepatitis B vaccination in children: the Taiwan experience. Pathol Biol (Paris) 2010, Epub ahead of print.

-12 Basuni AA, Butterworth L, Cooksley G, Locarnini S, Carman WF: Prevalence of HBsAg mutants and impact of hepatitis B infant immunisation in four pacific island countries. Vaccine 2004;22:2791-2799.

- 13 Cacciola I, Cerenzia G, Pollicino T, Squadrito G, Castellaneta S, Zanetti AR, Mieli-Vergani G, Raimondo G: Genomic heterogeneity of hepatitis B virus (HBV) and outcome of perinatal HBV infection. J Hepatol 2002; 36:426-432.

14 Su HX, Xu DZ, Li D, Zhang JX, Lu J, Choi BC Yan YP: Heterogeneity analysis of the hepatitis $\mathrm{B}$ virus genome in intrauterine infection. J Med Virol 2005;77:180-187.
15 Cheng H, Su H, Wang S, Shao Z, Men K, Li M, Li S, Zhang J, Xu J, Zhang H, Yan Y, Xu D: Association between genomic heterogeneity of hepatitis B virus and intrauterine infection. Virology 2009;387:168-175.

16 Norder H, Courouce AM, Magnius LO: Complete genomes, phylogenetic relatedness, and structural proteins of six strains of the hepatitis B virus, four of which represent two new genotypes. Virology 1994;198:489503.

-17 Edman JC, Gray P, Valenzuela P, Rall LB, Rutter WJ: Integration of hepatitis B virus sequences and their expression in a human hepatoma cell. Nature 1980;286:535-538.

18 Okamoto H, Tsuda F, Sakugawa H, Sastrosoewignjo RI, Imai M, Miyakawa Y, Mayumi M: Typing hepatitis B virus by homology in nucleotide sequence: comparison of surface antigen subtypes. J Gen Virol 1988;69:25752583.

19 Kobayashi M, Koike K: Complete nucleotide sequence of hepatitis B virus DNA of subtype adr and its conserved gene organization. Gene 1984;30:227-232.

20 Bichko V, Pushko P, Dreilina D, Pumpen P, Gren E: Subtype ayw variant of hepatitis $B$ virus: DNA primary structure analysis. Febs Lett 1985; 185:208-212.

-21 Stuyver L, De Gendt S, Van Geyt C, Zoulim F, Fried M, Schinazi RF, Rossau R: A new genotype of hepatitis $\mathrm{B}$ virus: complete genome and phylogenetic relatedness. J Gen Virol 2000;81:67-74.

22 Arauz-Ruiz P, Norder H, Robertson BH, Magnius LO: Genotype H: a new Amerindian genotype of hepatitis B virus revealed in central America. J Gen Virol 2002;83:20592073.

23 Luo KX: Hepatitis B Basic and Clinical Science, ed 2. Beijing, People's Medical Publishing House, 2001, pp 25-27.

24 Guo YB, Hou JL, Dai W, Luo KX, Karayiannis P: Establishment of the consensus sequence of hepatitis B virus prevailing in the mainland of China. Chin J Microbiol Immunol 1999;19:197-200.

25 Svicher V, Gori C, Trignetti M, Visca M, Micheli V, Bernassola M, Salpini R, Gubertini G, Longo R, Niero F, Ceccherini-Silberstein F, De Sanctis GM, Spano A, Cappiello G, Perno CF: The profile of mutational clusters associated with lamivudine resistance can be constrained by HBV genotypes. J Hepatol 2009;50:461-470.

26 Blanchet M, Sureau C: Infectivity determinants of the hepatitis $\mathrm{B}$ virus pre-s domain are confined to the $\mathrm{N}$-terminal 75 amino acid residues. J Virol 2007;81:5841-5849.

$\checkmark 27$ Jaoude GA, Sureau C: Role of the antigenic loop of the hepatitis B virus envelope proteins in infectivity of hepatitis delta virus. J Virol 2005;79:10460-10466.
28 Xia GL, Jia ZY, Liu HB, Li RC, Cao HS, Liu CB: Characterization and distribution of hepatitis B virus genotypes and subtypes in 4 provinces of China. Chin J Epidemiol 2001; 22:348-351

29 McMahon BJ: The influence of hepatitis B virus genotype and subgenotype on the natural history of chronic hepatitis B. Hepatol Int 2009;3:334-342.

-30 Norder H, Courouce AM, Coursaget P, Echevarria JM, Lee SD, Mushahwar IK, Robertson BH, Locarnini S, Magnius LO: Genetic diversity of hepatitis B virus strains derived worldwide: genotypes, subgenotypes, and HBsAg subtypes. Intervirology 2004; 47: 289-309.

31 Gao JW, Li YJ, Zhuang H, Li J, Wang J, Dong QM, Cheng YJ: Distribution of hepatitis B virus genotypes in patients with chronic hepatitis B virus infection among 11 cities of China. Chin J Epidemiol 2007;28:315-318.

32 Shepard CW, Simard EP, Finelli L, Fiore AE, Bell BP: Hepatitis B virus infection: epidemiology and vaccination. Epidemiol Rev 2006; 28:112-125

33 Ozdil B, Cosar AM, Akkiz H, Sandikci MU, Kece C: Negative correlation between viral load and HBsAg levels in chronic HBV-infected patients. Arch Virol 2009; 154:14511455.

>34 Xu H, Peng M, Qing Y, Ling N, Lan Y, Liang Z, Cai D, Li Y, Ren H: A quasi species of the pre-s/s gene and mutations of enhancer II/ core promoter/pre-c in mothers and their children infected with hepatitis $B$ virus via mother-to-infant transmission. J Infect Dis 2006;193:88-97.

35 Gerlich WH: Breakthrough of hepatitis B virus escape mutants after vaccination and virus reactivation. J Clin Virol 2006;36(suppl 1):S18-S22.

36 McMahon BJ, Bruden DL, Peterson KM, Bulkow LR, Parkinson AJ, Nainan O, et al: Antibody levels and protection after hepatitis B vaccination: results of a 15-year followup. Ann Intern Med 2005;142:333-341.

>37 Liu SL, Dong Y, Zhang L, Li MW, Wo JE, Lu LW, Chen ZJ: Influence of HBV gene heterogeneity on the failure of immunization with $\mathrm{HBV}$ vaccines in eastern China. Arch Virol 2009; 154:437-443.

-38 Hsu HY, Chang MH, Ni YH, Lin HH, Wang SM, Chen DS: Surface gene mutants of hepatitis B virus in infants who develop acute or chronic infections despite immunoprophylaxis. Hepatology 1997;26:786-791.

39 Szomor KN, Denes A, Garai E, Rusvai E, Berencsi G, Takacs M: Mutation spectra of the surface-protein-coding region of the $\mathrm{HBV}$ genome in HBV-vaccinated and nonvaccinated individuals in Hungary. Arch Virol 2008; $153: 1885-1892$. 